\title{
POSING QUESTIONS AND POLICY SUGGESTIONS: AUTONOMOUS VEHICLES \& CLIMATE CHANGE
}

\author{
Melody Barnard, Robert Hitt, Michael Norton, Yi-Ching Lee \\ George Mason University \\ Fairfax, VA, USA \\ Email: ylee65@gmu.edu
}

\begin{abstract}
Summary: The introduction of autonomous vehicles (AVs) is projected to increase safety and efficiency of transportation. However, climate change poses a challenge to the smooth integration of AVs to current transportation infrastructure. Increased extreme weather events, higher precipitation and temperature, and damages to infrastructure are challenges AVs will face. Therefore, the authors advocate for Planned Adaptive Regulation, and raise questions that they feel policymakers and driving assessment should consider.
\end{abstract}

\section{INTRODUCTION}

The NIH (National Institute of Health), CDC (Center for Disease Control), EPA (Environmental Protection Agency), NASA (National Aeronautics and Space Administration), IPCC (Intergovernmental Panel on Climate Change), and other organizations throughout the world have all acknowledged and warned the public about the planet's warming (IPCC, 2018; CDC, 2018; EPA, 2018; NASA, 2018; NIH, 2018). Furthermore, there is more than a $95 \%$ probability the current warming trend is the result of human activity since the start of industrialization (NASA, 2018). The evidence for climate change is empirical and documented in a large number of fields. For example, Thompson (2010)'s glacier research has shown consistent, rapid melting of ice at increasing rates in polar and high elevation ice regions from 16 countries over the last 35 years. Furthermore, as icy regions melt, they expose darker areas (i.e. dirt, rock) which reflect less solar energy, and tundra permafrost melts to release carbon dioxide from rotted organic material, thus exacerbating the problem. Higher global temperatures also mean dryer forests, forest fires, and carbon release from the stored carbon in the ground (Abatzoglou \& Williams, 2016). NASA (2018) have consolidated work from a large number of sources to provide more detailed evidence and is a good resource for further reading on the topic. As of October 2018, the IPCC estimates we have 12 years max to make drastic changes to our energy use (IPCC, 2018).

The transportation sector is particularly vulnerable to meteorological hazards (Thornes, 1992). Climate change is expected to bring an increased amount of weather hazards that the transport infrastructure is sensitive to, such as extreme weather events, high temperatures, and heavy rain (Jaroszweski, Chapman, \& Petts, 2010). While much research has been aimed at making AVs more energy efficient and less harmful for the environment (Fagnant \& Kockelman, 2015; Hu et al., 2016; Schafer, Kyle, \& Pietzcker, 2016; Evans \& Russ, 2018), there has been less focus on how climate conditions will impact the development and implementation of AVs. Several commentators have identified vulnerabilities that AVs face against poor weather conditions (see Stock, 2018 and Marshall, 2017), and we believe this issue deserves more attention both on a technological and regulatory level. 
PROCEEDINGS of the Tenth International Driving Symposium on Human Factors in Driver Assessment, Training and Vehicle Design

\section{POLICY RECOMMENDATIONS AND CHALLENGES}

\section{Recommendations}

1. Local and federal government should consider proactively protecting infrastructure from these extremes to minimize financial burden over time.

Much of the current transportation infrastructure has been designed under the assumption that climate is steady over time. However, increased temperature and weather extremes due to climate change introduce new threats to this design framework (Milly et al., 2008).

Developments in these areas highlight the importance of safe pavement conditions for AV implementation. Under intensive heat conditions, pavement will soften and expand, causing potholes to form. Additionally, there will be limitations on construction activities due to the unsafe working conditions (EPA, 2018). Through a systems dynamics model, Mallick et al. (2014) show that pavement maintenance costs increase greatly with the added variable of climate change.

A changing climate will also have an effect on current precipitation patterns. An increase in precipitation is associated with greater traffic congestion (Hambly, Andrey, Mills, \& Fletcher, 2013). While it's generally understood that inclement weather is an area in which AV's detection capabilities suffer, no significant research has been done comparing current AV technology with human drivers in adverse conditions. Preparing for these damages and determining the most efficient plans for travel and maintenance require accurate data on climate, pavement condition, and travel behaviors. Preparing for the long term viability of AVs in our current infrastructure creates urgency on meeting these needs.

2. V2V networks should be improved to actively communicate weather conditions and poor infrastructure to other AVs and humans.

Douglas et al. (2017) summarize strategies for addressing environmental challenges through the use of information technologies such as advanced weather and mobile observations, crowdsourcing, and big data analysis tools; all of which allow AVs to be capable of contributing towards or at least benefiting from constant monitoring of environmental challenges. Through the use of GPS, Radar, Lidar, and/or additional sensors, AVs are capable of reading current conditions of temperature, visibility, pavement, and traffic conditions (Varghese \& Boone, 2015). Equipping AVs with state-of-the-art sensors is critical for connected fleets of AVs to collect and communicate information on current infrastructure and weather conditions through the use of vehicle-to-vehicle (V2V) networks. Communicating roadway and weather conditions through V2V networks in short range is through wireless technology, although constructing long range communication links without sacrificing quality of the data and message transmission is still a challenge (Yan \& Rawat, 2017). The IEEE 802.11p standard for vehicular communication, known as the Dedicated Short Range Communication (DSRC), currently enables vehicular communication for safety and infotainment applications (media, navigation applications, map data, etc.) (Festag, 2015). Increasing the strength of this communication standard for faster association and lower communication latency is an important task for helping AVs navigate poor 
weather and infrastructure conditions in real time, and also will aid researchers in developing further infrastructure solutions (Mahoney \& O’Sullivan, 2013).

3. AV design should take temperature and precipitation extremes into consideration when calculating the rate of deterioration for their machines.

Current AV development has largely been focused on getting experiential data for their algorithms to learn from, and has been less focused on the durability of their vehicles in poor infrastructure and weather. The average age of passenger cars and light trucks in 2016 was 11.6 years, as announced by the Bureau of Transportation Statistics (2016). However, the length of time a vehicle is used is impacted by vehicle care, check-ups, the quality of the vehicle, and primarily how often and long the vehicle is used for (DeMuro, 2015). Precipitation and temperature extremes, exacerbates the problem of AV life-span. Furthermore, most AV companies are working in platoons, typically ride-hailing structures (Waymo, Uber, etc.); this constant use, compared to conventional vehicles that spend most of their time unused, will significantly decrease the life-span of the vehicle.

\section{Challenges}

There are two key challenges that need to be addressed to put the above recommendations in place: the difficulty of drafting legislation that will accommodate for technological progress and the cost of government action. In response, we suggest planned adaptive regulation and a government-subsidized platoon of $\mathrm{AVs}$ with advanced $\mathrm{V} 2 \mathrm{~V}$ communication.

Cost is a pivotal issue. Shifting the societal model of transportation from personally owned vehicles to a ridesharing-based model would theoretically allow for a more efficient usage of government subsidies; rather than funding personally-owned vehicles that might sit in garages more than half of the time, the government can invest in a distributed ridesharing fleet that can be more easily utilized to peak efficiency (Brownell et al., 2014). A government-subsidized, ecofriendly, autonomous fleet could also report back weather and infrastructure conditions to local entities via $\mathrm{V} 2 \mathrm{~V}$ communications as we suggest above.

Planned adaptive regulation may better serve a society where scientific understanding and technology is constantly evolving at a pace too fast for traditional legislation, especially when it concerns matters of such importance as climate change. Planned adaptive regulation is a legislative tool which allows statutes to be revised as knowledge regarding the concerned issues is updated (McCray, Oye, \& Petersen, 2010). Planned adaptive regulation is designed to accommodate a changing landscape by setting dates where the legislation will be reviewed ahead of time, with feedback from the field about its effectiveness and weaknesses. Currently, the burden of handling AV deterioration is largely on automotive companies, enforced only by the public's lack of trust in the new technology. However using planned adaptive regulation could incorporate limitations about material-use and safe length of use, given real data from the roads.

The recommendations above are more open-ended goals, but a great place to start is giving the NHTSA power to enforce AV regulations, as currently they can only suggest guidelines. The current top three AV companies closest to developing fully functional AVs, as ranked by 
Navigant's AV leaderboard (2019) are Waymo, General Motors (GM)/Cruise and Ford AV. Each has crash tested their main vehicles according to FMVSS (Federal Motor Vehicle Safety Standards), however adherence was voluntary (General Motors, 2018; Waymo, 2018; Ford, 2018). The SELF DRIVE act, which provides the base work for AV regulation, has passed the House and awaits approval in the Senate (H.R.3388, 2017). On the state level, only 15 states have enacted $18 \mathrm{AV}$ related bills, as of March 19, 2019 (National Conference for State Legislature). Passing basic laws on AVs must be the first step. However, the technology has and will develop rapidly, which drives the need to address the concerns raised in this paper. Along with big ticket concerns like cybersecurity and technological reliability, climate change needs to have more voice in the conversation when it comes to infrastructure, V2V communication, and durability.

\section{CONCLUSION}

This paper has described how climate change will impact AV development and implementation; in particular, the impacts of weather extremes on the durability of AVs and infrastructure. This is by no means an exhaustive overview of the impacts of climate change on AVs, but aims at beginning a dialogue on the topic. We proposed solutions to the unique challenges in developing wide-scale policy reforms to ensure safety and efficiency for a dynamically changing transportation sector that will have to accommodate climate change and AVs in coming years. Furthermore, we suggest adopting platoon-first incentives as a means of being eco- and costfriendly.

\section{ACKNOWLEDGMENTS}

We thank the OSCAR office at George Mason University for supporting the first three authors via the federal work-study program for undergraduate students.

\section{REFERENCES}

Abatzoglou, J. T., \& Williams, A. P. (2016). Impact of anthropogenic climate change on wildfire across western US forests. Proceedings of the National Academy of Sciences, 113(42), 11770-11775.

Brownell, C., \& Kornhauser, A. (2014). A driverless alternative: fleet size and cost requirements for a statewide autonomous taxi network in New Jersey. Transportation Research Record: Journal of the Transportation Research Board, (2416), 73-81.

Bureau of Transportation Statistics. (2016). Average Age of Automobiles and Trucks in Operation in the United States.

CDC - Climate Change and Public Health (2018, October 31). Centers for Disease Control and Prevention. U.S. Department of Health \& Human Services.

DeMuro, D. (2015). Buying a Car: How Long Can You Expect a Car to Last? Autotrader. 
Douglas, E., Jacobs, J., Hayhoe, K., Silka, L., Daniel, J., Collins, M., ... Wake, C. (2017). Progress and challenges in incorporating climate change information into transportation research and design. Journal of Infrastructure Systems, 23(4), 4017018. https://doi.org/10.1061/(ASCE)IS.1943-555X.0000377

Evans, B., \& Roberts, R. (2017). Benedict Evans on the Future of Cars - Econlib.

Fagnant, D. J., \& Kockelman, K. (2015). Preparing a nation for autonomous vehicles: Opportunities, barriers and policy recommendations. Transportation Research Part A: Policy and Practice, 77, 167-181. https://doi.org/10.1016/j.tra.2015.04.003

Festag, A. (2015). Standards for vehicular communication-from IEEE 802.11p to 5G. $E \& I$ Elektrotechnik Und Informationstechnik, 132(7), 409-416. https://doi.org/10.1007/s00502-015-0343-0

Ford. (2018). A Matter of Trust: Ford's Approach to Developing Self-Driving Vehicles.

General Motors. (2018). 2018 Self-Driving Safety Report. Global Warming of 1.5 C. (2018). (No. IPCC-SR15).

Hambly, D., Andrey, J., Mills, B., \& Fletcher, C. (2013). Projected implications of climate change for road safety in Greater Vancouver, Canada. Climatic Change, 116(3), 613629. https://doi.org/10.1007/s10584-012-0499-0

Hu, J., Shao, Y., Sun, Z., Wang, M., Bared, J., \& Huang, P. (2016). Integrated optimal ecodriving on rolling terrain for hybrid electric vehicle with vehicle-infrastructure communication. Transportation Research Part C: Emerging Technologies, 68, 228-244. https://doi.org/10.1016/j.trc.2016.04.009

Jaroszweski, D., Chapman, L., \& Petts, J. (2010). Assessing the potential impact of climate change on transportation: the need for an interdisciplinary approach. Journal of Transport Geography, 18(2). Retrieved from https://trid.trb.org/view/913295

Koetse, M. J., \& Rietveld, P. (2009). The impact of climate change and weather on transport: An overview of empirical findings. Transportation Research Part D: Transport and Environment, 14(3), 205-221. doi:10.1016/j.trd.2008.12.004

Latta, R. E. (2017, September 7). H.R.3388 - 115th Congress (2017-2018): SELF DRIVE Act.

Marshall, A. (2017, October 27). To Let Self-Driving Cars Go Anywhere, You Must Train Them Everywhere.

Mahoney, W. P., \& O’Sullivan, J. M. (2013). Realizing the potential of vehicle-based observations. Bulletin of the American Meteorological Society, 94(7), 1007-1018. https://doi.org/10.1175/BAMS-D-12-00044.1

McCray, L. E., Oye, K. A., \& Petersen, A. C. (2010). Planned adaptation in risk regulation: An initial survey of US environmental, health, and safety regulation. Technological Forecasting and Social Change, 77(6), 951-959. https://doi.org/10.1016/j.techfore.2009.12.001

Milly, P. C. D., Betancourt, J., Falkenmark, M., Hirsch, R. M., Kundzewicz, Z. W., Lettenmaier, D. P., \& Stouffer, R. J. (2008). Stationarity Is Dead: Whither Water Management? Science, 319(5863), 573-574. https://doi.org/10.1126/science.1151915 
National Conference of State Legislature. (2019). Autonomous Vehicles | Self-Driving Vehicles Enacted Legislation [Legislative Database]

Navigant Research Leaderboard (2019). Automated Driving Vehicles.

Stock, Kyle. (2018, September 17). Self-Driving Cars Still Can’t Handle Bad Weather.

Thompson, L. G. (2010). Climate Change: The evidence and our options. The Behavior Analyst, $33(2), 153-170$.

Thornes, J. E. (1992). The impact of weather and climate on transport in the UK. Progress in Physical Geography: Earth and Environment, 16(2), 187-208. https://doi.org/10.1177/030913339201600202

US EPA (2018). Climate Impacts on Transportation. Overviews and Factsheets.

Yan, G., \& Rawat, D. B. (2017). Vehicle-to-vehicle connectivity analysis for vehicular ad-hoc networks. Ad Hoc Networks, 58, 25-35. https://doi.org/10.1016/j.adhoc.2016.11.017

Varghese, J. Z., \& Boone, R. G. (2015, September). Overview of autonomous vehicle sensors and systems. In Proceedings of the 2015 International Conference on Operations Excellence and Service Engineering (pp. 178-191). IOEM Society.

Waymo. (2018). On the Road to Fully Self-Driving: Waymo Safety Report. 